\title{
Valores políticos e a construção de sistemas públicos de saúde no Brasil e nos Estados Unidos
}

\author{
DANIEL CAPISTRANo \\ Doutor em Estudos Comparados (Universidade de Brasília) \\ Pesquisador do Instituto Nacional de Estudos e Pesquisas Educacionais Anísio Teixeira \\ danielcapistrano@gmail.com
}

\begin{abstract}
Resumo $\mathrm{O}$ artigo busca explorar a relação entre visões políticas predominantes na sociedade e as propostas de construção de um sistema nacional de saúde no Brasil e nos Estados Unidos. Segundo dados de surveys recentes, a opinião pública sobre o papel do governo na saúde pública difere consideravelmente entre brasileiros e norte-americanos. Essas opiniões estão intrinsecamente ligadas às características da cultura política desses dois países. Analisando discursos e narrativas presentes nos debates acerca da construção do Sistema Único de Saúde, no Brasil, e do plano norte-americano de reforma da saúde, da década de 1990, o presente trabalho discute como elementos desses discursos expressaram aspectos da cultura política das sociedades brasileira e norte-americana conforme se indica na literatura sobre o tema nas ciências sociais. $\mathrm{O}$ artigo contribui para a reflexão sobre como características culturais mais subjetivas permeiam o debate sobre políticas públicas e trazem elementos importantes para se compreender decisões políticas.
\end{abstract}

Palavras-chave: cultura política, políticas de saúde, Brasil, Estados Unidos

\section{Introdução}

$\mathrm{O}$

ESTUDO AQUI APRESENTADO trata da relação entre cultura política e políticas públicas por meio da análise comparada de dois casos específicos do Brasil e dos Estados Unidos. O tópico abordado apresenta-se como um desafio tanto para a perspectiva culturalista quanto para a perspectiva institucionalista das ciências sociais. Os culturalistas, por um lado, têm dedicado-se a ir além da mera indicação de que características culturais exercem influência sobre o sistema político, e um esforço notável tem sido empenhado nas duas últimas décadas para demonstrar de que maneira essa influência é exercida. Por outro lado, à perspectiva institucionalista tem-se imposto o obstáculo de explicação dos motivos de arranjos institucionais semelhantes terem impacto e comportamentos distintos em culturas diferentes.

Os resultados desse estudo comparativo apresentam evidências de como a cultura política de uma dada sociedade está relacionada com a elaboração de políticas públicas. O método comparado utilizado aponta como o contraste entre aspectos culturais das sociedades brasileira e norte-americana pode explicar diferentes caminhos tomados por esses países na formulação de seus respectivos sistemas de saúde pública. 

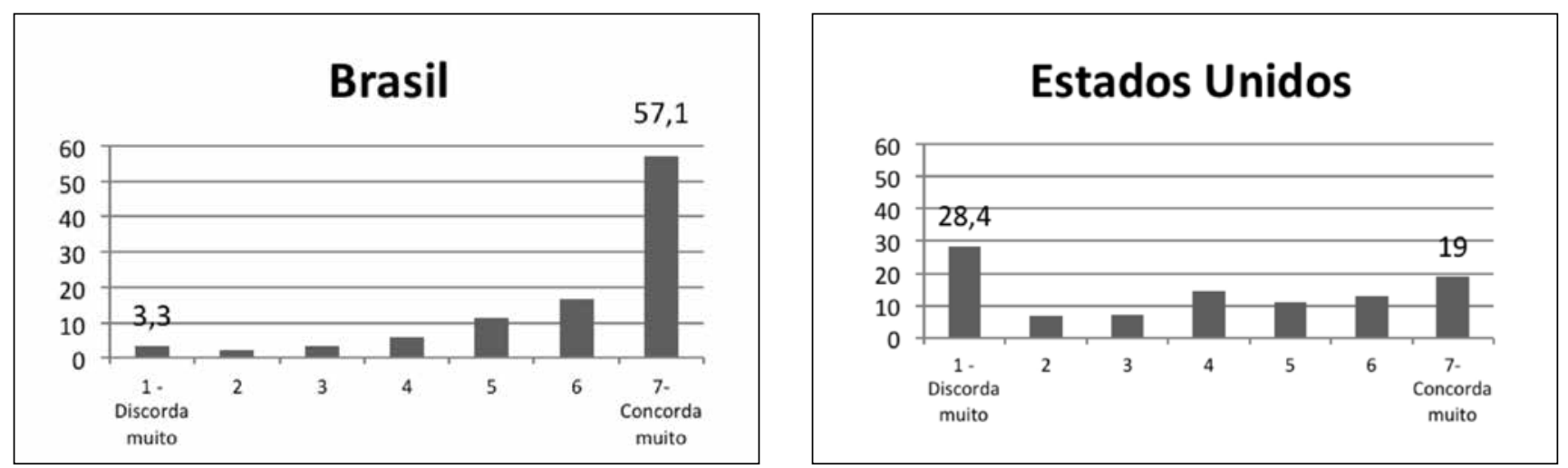

Gráfico 1- Percentual de respostas de concordância com a afirmação de que "O Estado, mais do que o setor privado, deve ser o responsável pelo provimento de serviços de saúde (hospitais)" - Brasil e EUA (2012)

Fonte: The AmericasBarometer by the Latin American Public Opinion Project (LAPOP), www.lapopsurveys.org.

Um exemplo ilustrativo das distintas características da cultura política no Brasil e nos Estados Unidos é o debate acerca da implantação de um sistema nacional de saúde em anos recentes. Conforme apresentado no gráfico acima, utilizando dados do Barômetro das Américas $^{1}$ de 2012, os brasileiros tendem a concordar mais com a presença do Estado enquanto provedor dos serviços de saúde da população se comparados aos norte-americanos.

O que poderia explicar essas diferenças entre o Brasil e os Estados Unidos no que concerne às opiniões sobre o papel do governo na saúde pública? Nós argumentamos que características da cultura política de ambas as sociedades podem explicar parte dessas opiniões. Cultura política é definida como um conjunto de crenças, valores e atitudes que os indivíduos e grupos compartilham sobre o sistema politico. As ciências sociais apresentam diversas formas de se acessar a cultura política que vai desde pesquisas de tipo survey à etnografia. A primeira parte deste texto procura descrever alguns elementos importantes dessa dimensão cultural do Brasil e dos Estados Unidos por meio do trabalho de reconhecidos intérpretes dessas sociedades. Em seguida, na segunda parte, esses aspectos da cultura política dos dois países são relacionados às orientações sobre o papel do Estado no sistema de saúde, por meio da análise dos principais debates que arrazoaram as propostas de reforma de saúde no Brasil e nos Estados Unidos.

\section{Cultura política brasileira}

Ao se tratar de um país com uma vasta extensão territorial e alta heterogeneidade social, torna-se muito complexo identificar traços culturais comuns entre os habitantes do Brasil por um largo período de sua história. Somente após a segunda metade do Século XX, com a massificação de mídias como o rádio e a televisão, é que considerável parte da população passou a compartilhar linguagem, símbolos e significados comuns. No entanto, autores como Gilberto Freyre, Sérgio Buarque de Holanda e Raymundo Faoro trazem elementos concretos da história brasileira anterior ao Século XX que contribuíram para a gênese da cultura nacional.

Em uma de suas principais obras, Casa-Grande $\mathcal{E}$ Senzala, Gilberto Freyre destaca as relações sociais do Brasil colonial sob uma perspectiva bastante incomum para a época em que escrevia, a primeira metade do século XX. Sua principal tese é de que houve uma relativa harmonia no estabelecimento das relações raciais do Brasil, principalmente se comparada àquelas observadas no sul dos Estados Unidos. Atribuindo a uma conjuntura de fatores como, por exemplo, a existência de um peculiar "catolicismo luso-português"; como afirma Freye (2003, p.438) "Verificou-se entre nós uma profunda confraternização de valores e de sentimentos. Predominantemente coletivistas, os vindos das senzalas; puxando para o individualismo e para o privativismo, os das casas-grandes."

Apesar dessa tese de harmonia nas relações raciais vir sendo contestada desde então, a "descoberta" desse hibridismo na gênese da cultura brasileira serviu de base para diversos outros estudos em ciências sociais no Brasil. Acima de tudo, seu trabalho serviu para um rompimento simbólico com as explicações geográficas e biológicas da sociedade brasileira, predominantes até então, em direção a uma explicação embasada na história e na cultura do povo brasileiro.

Sérgio Buarque de Holanda, por sua vez, vai além da análise particularista do núcleo familiar brasileiro 
realizada por Freyre, e observa o impacto dessas relações privadas sobre o processo de modernização social no Brasil. Nesse sentido, o autor pensa o surgimento do Estado como um elemento que, em tese, deveria ser uma "transcendência" do plano particular, familiar, havendo uma oposição entre a dimensão individual e a dimensão do Estado. Isto é, para Holanda (1995, p. 141).

Só pela transgressão da ordem doméstica e familiar é que nasce o Estado e que o simples indivíduo se faz cidadão, contribuinte, eleitor, elegível, recrutável e responsável, ante as leis da Cidade.

No entanto, observa Holanda (1995, p.82), características típicas da formação social brasileira vão de encontro a esse processo. Ao passo em que a dinâmica de construção da sociedade é fortemente marcada por traços personalistas e mandonistas.

O resultado era predominarem, em toda a vida social, sentimentos próprios a vida doméstica, naturalmente particularista e anti-política, uma invasão do público pelo privado, do Estado pela família.

Isso não indica haver, então, uma preferência pela ação individual e particularista em contraposição a ação do Estado, mas sim a contaminação da esfera pública por práticas privadas, o que dá origem a uma conhecida caraterística da cultura política brasileira: o patrimonialismo.

Em uma de suas mais célebres obras, Raymundo Faoro (2001) apresenta uma extensa análise sobre a história política brasileira. Para Faoro, o patrimonialismo é uma das principais características da formação política brasileira, influente em todos os grandes episódios desde Dom João I até a era Vargas, e cujo fundamento principal esteve ligado ao problema do poder do Estado sobre a economia. Em sua perspectiva, Faoro (2001, p. 33) afirma que

O problema não seria pertinente a este ensaio se o feudalismo não houvesse deixado, no seu cortejo funerário, vivo e persistente legado, capaz de prefixar os rumos do Estado moderno. Patrimonial e não feudal o mundo português, cujos ecos soam no mundo brasileiro atual, as relações entre o homem e o poder são de outra feição, bem como de outra índole a natureza da ordem econômica, ainda hoje persistente, obstinadamente persistente.

A partir dessa apreciação mais centrada no caráter patrimonialista da formação política brasileira, Raymundo Faoro elabora o conceito de capitalismo politicamente orientado para explicar o surgimento e a consolidação dessa ordem patrimonialista. Para Faoro (2001, p. 866) o individualismo, característico de sistemas políticos derivados das revoluções burguesas no fim do feudalismo - ausente na península ibérica e no
Brasil, teve de ser suplantado ou incorporado a esse ambiente onde Estado dirigiu o capitalismo:

O capitalismo politicamente orientado - o capitalismo político, ou o pré-capitalismo - , centro da aventura, da conquista e da colonização moldou a realidade estatal, sobrevivendo, e incorporando na sobrevivência o capitalismo moderno, de índole industrial, racional na técnica e fundado na liberdade do indivíduo - liberdade de negociar, de contratar, de gerir a propriedade sob a garantia das instituições. A comunidade política conduz, comanda, supervisiona os negócios, como negócios privados seus, na origem, como negócios públicos depois, em linhas que se demarcam gradualmente. O súdito, a sociedade, se compreendem no âmbito de um aparelhamento a explorar, a manipular, a tosquiar nos casos extremos.

Desta feita, o autor apresenta a imagem de um país cuja história é marcada por uma divisão social aguda entre os que detém o poder e aqueles que, guiados pelo prisma da tradição, dão apoio e legitimam a dominação desse estamento. Nas palavras de Faoro (2001, p. 876-877)

Duas categorias justapostas convivem, uma cultivada e letrada, outra, primária, entregue aos seus deuses primitivos, entre os quais, vez ou outra, se encarna o bom príncipe. [...]povo quer a proteção do Estado, parasitando-o, enquanto o Estado mantém a menoridade popular, sobre ela imperando. No plano psicológico, a dualidade oscila entre a decepção e o engodo.

Ao comentar a referida obra de Faoro, Fernando Henrique Cardoso (2013, p. 73) pondera que embora esteja de acordo com o autor em sua análise sobre a força social do Estado patrimonialista "reconhecendo que o patrimonialismo ainda pesa em nossa cultura e em nossa práticas políticas", acredita que é possível dar maior ênfase ao contraponto crescente que "valores de individualismo e liberdade na sociedade" engendrados pela globalização, os regimes democráticos e a mídia independente impõem à cultura patrimonialista.

Almeida (2007, p. 193) também acredita que uma mudança nos valores pró-Estado está em curso no Brasil. Embora realize o diagnóstico de que entre os brasileiros exista um alto grau de "estatismo" em decorrência de toda história de formação cultural brasileira, o autor afirma que "Para quem deseja menos Estado, resta apenas o consolo de que esse é o destino da opinião pública no Brasil. É um processo longo, porém inexorável: também nesse aspecto, à medida que a escolaridade aumentar, o apoio social à presença do Estado na economia tenderá a tornar-se cada vez menor".

Embora o diagnóstico de Almeida (2007) verifique-se empiricamente, não existem evidências que apoiem sua previsão de que esse estatismo tende a 
diminuir em virtude do aumento de escolarização da população, conforme demonstrado em trabalho anterior ${ }^{2}$.

\section{Cultura política norte-americana}

No filme "The Man Who Shot Liberty Valance", de John Ford, gravado em 1962, há uma cena em que o personagem interpretado por John Wayne contracena com um advogado que recém fora assaltado e buscava as autoridades para encontrar e prender o assaltante. Ao acudi-lo, o personagem de Wayne sugere que a vítima busque uma arma e o repreende: "Eu sei que esses livros da lei valem muito para você, mas não aqui. Aqui um homem resolve os seu próprios problemas" 3 .

Essa fala expressa o espírito do homem que é responsável por seus próprios atos e que a ele deve ser garantida somente a liberdade de escolher e agir. Esse espírito é recorrentemente exaltado na cultura norte-americana e expressa o que ficou conhecido como o individualismo persistente (rugged individualism), uma das características mais debatidas da cultura norte-americana.

Esse debate remonta a meados do Século XIX e suas bases podem ser encontradas no trabalho de Alexis de Tocqueville. Enviado em 1831 aos Estados Unidos para traçar um perfil do sistema prisional desse país, Tocqueville foi além de suas atribuições e realizou observações sobre a economia, o sistema político e sociedade norte-americanas que o tornaram um dos pioneiros e mais célebres comentadores da cultura política norte-americana.

A obra "Democracia na América", resultante das observações de Tocqueville (2005, p. 303), por exemplo, faz um exame do cotidiano e da ação de homens comuns como elementos fundamentais para a interpretação do sistema político, como aponta o trecho a seguir:

São portanto particularmente os costumes que tomam os americanos dos Estados Unidos, únicos entre todos os americanos, capazes de suportar o império da democracia; e são também eles que fazem que as diversas democracias anglo-americanas sejam mais ou menos regradas e prósperas.

Tal perspectiva pode ser considerada inovadora frente aos estudos políticos da sociedade norte-americana que até então se pautavam pela discussão de aspectos jurídicos ou filosóficos. Neste autor já está presente a ideia de que os comportamentos, as interpretações e as formas de pensar - "les moeurs" - presentes na sociedade civil constituem fatores decisivos para o surgimento e a estabilidade democrática. Tocqueville (2005, p. 338) expõe que
Entendo aqui a expressão costumes no sentido que os antigos davam à palavra mores. Não a aplico apenas aos costumes propriamente ditos, que poderíamos chamar hábitos do coração, mas também às diferentes noções que os homens possuem, às diversas opiniões correntes entre eles e ao conjunto das idéias de que se formam os hábitos do espírito.

É importante notar que sua análise da sociedade norte-americana é altamente marcada por um contraste com a sociedade francesa. Um dos grandes impactos de alteridade de Tocqueville, perceptível em sua obra, é quanto ao individualismo na sociedade norte-americana. Para o autor, esses costumes individualistas estão ligados à ideia de que as pessoas deveriam ter autonomia para lidar com seus próprios problemas, para que cada um viva de acordo com suas próprias regras. Ao verificar a força do associativismo nos Estados Unidos, Tocqueville (2005, p. 227) relata que

\begin{abstract}
A independência individual nelas [associações] encontra seu lugar: como na sociedade, todos os homens nelas caminham ao mesmo tempo para o mesmo objetivo, mas cada um não é obrigado a marchar exatamente pelos mesmos caminhos. Não se faz nelas o sacrifício de sua vontade e de sua razão, mas aplica-se sua vontade e sua razão para o êxito de uma empresa comum.
\end{abstract}

Nos mesmos aspectos da sociedade norte-americana que despertaram a surpresa e a atenção do jovem pesquisador francês, residem também os fundamentos da tese do "excepcionalismo americano" debatida há décadas nas ciências sociais. Essa tese que encontra no trabalho do sociólogo Seymour Martin Lipset (1996) uma de suas maiores expressões, argumenta que a sociedade que habita os Estados Unidos possui um caráter qualitativamente distinto de outras nações, dada a conjunção de fatores históricos excepcionais que marcaram a sua história.

Ao investigar a razão do socialismo não haver encontrado uma aceitação mais contundente dentro da sociedade americana, Lipset (1996, p. 87, tradução nossa) atribui a fatores sociais ligados a esse excepcionalismo, entre eles.

\begin{abstract}
A ênfase do sistema de valores sobre o individualismo e anti-estatismo derivado do passado sectário e dos valores revolucionários do protestantismo norte-americano, que implicou uma oposição a um Estado de bem-estar social ou fortemente coletivista.
\end{abstract}

Nessa mesma direção, em um estudo que examina as principais dimensões que determinam as diferen- 
ças nos padrões de políticas públicas entre os países da Europa ocidental, Canadá e os Estados Unidos, King (1973, p. 418, tradução nossa) afirma que

... “...quase todo norte-americano aceita que o Estado
tem muito pouca - e deve ter muito pouca - responsa-
bilidade operacional direta: que o Estado deveria optar
pelo papel de árbitro em vez do de gestor [...] Valores
culturais norte-americanos contem um dilema latente,
Por um lado eles colocam grande ênfase - bem maior
que colocam os valores Europeus - em igualdade e na
oferta de oportunidades para mobilidade social ascen-
dente. Por outro lado, eles dão igualmente grande ênfase
ao sustento de uma ordem social altamente individualista.

Embora seja demasiadamente simplista descrever uma cultura política tão heterogênea como a norte-americana por meio de tal parca seleção de seus intérpretes, é possível identificar nessas visões sobre os norte-americanos algumas características culturais que servem de guia para a formação das orientações políticas nos Estados Unidos.

\section{O Brasil e a construção do Sistema Único de Saúde}

A partir das aludidas interpretações acerca da cultura política desses dois países, buscaremos agora traços latentes dessas características da cultura política em dois momentos específicos da história sócio-política desses dois países.

O Brasil possui um sistema público de saúde de abrangência universal e de responsabilidade do Estado. Conforme previsto em sua constituição, no artigo 196,

A saúde é direito de todos e dever do Estado, garantido mediante políticas sociais e econômicas que visem à redução dos riscos de doença e de outros agravos e o acesso universal e igualitário às ações e serviços para sua promoção, proteção e recuperação ${ }^{4}$

A principal política de Estado que visa a garantia desse direito é o Sistema Único de Saúde (SUS), que foi estabelecido no início da década de 1990. O período que antecede a instauração desse sistema é marcado por uma discreta cobertura social do sistema público de saúde. Universalmente, o Ministério da Saúde em articulação com estados e municípios se concentrava apenas em ações de prevenção de doenças (campanhas de vacinação, saneamento, entre outras). A maior parte do sistema de assistência de saúde pública era gerenciada pelo INAMPS (Instituto Nacional de Assistência Mé- dica e Previdência Social) que garantia assistência aos empregados formais e seus dependentes. Isto é, aqueles trabalhadores fora da economia formal ou indivíduos sem emprego tinham que pagar por assistência médica ou reclamar o amparo de instituições filantrópicas.

$\mathrm{Na}$ década de 1970, começa a tomar corpo no Brasil a defesa de uma reforma sanitária. De forma semelhante àquelas propostas em países europeus, especialmente na Itália, os defensores de uma reforma sanitária no Brasil tinham como objetivo a discussão da reformulação normativa e institucional do sistema de assistência de saúde aos cidadãos. Essa defesa da Reforma no Brasil tem como marcos históricos principais a fundação do Centro Brasileiro de Estudos de Saúde (CEBES), em 1976, e da Associação Brasileira de Pós-Graduação em Saúde Coletiva (ABRASCO), em 1979, como "instituições empenhadas na universalidade e equidade da assistência à saúde" 5 .

Toda a discussão gerada pela defesa da Reforma Sanitária encontra no processo de abertura democrática e no debate da nova constituição uma forma de canalizar as ideias para transformação das políticas de saúde vigentes. A VIII Conferência Nacional de Saúde (CNS 8), realizada em 1986, foi a arena principal do debate entre as distintas proposições relativas à reforma do sistema público de saúde no Brasil antes da Assembleia Constituinte. Embora tenha sido a oitava vez que essa conferência tenha sido realizada, desde seu início na era Vargas, essa foi a primeira que contou com uma ampla participação popular. Conforme estabeleceu o regimento especial da conferência (CNS, 1986), tomaram parte na condição de delegados os seguintes atores: representantes de ministérios, secretarias estaduais e municipais, parlamentares, representantes de sindicados, entidades trabalhistas e representantes de diversas associações da sociedade civil. $\mathrm{O}$ evento final, ocorrido na cidade de Brasília, registrou a presença de mais de quatro mil delegados vindos de todo o país.

Ao tratar do contexto sociopolítico da segunda metade da década de 1980 que ambientaram a conferência nacional de saúde, Faleiros et. al. (2006, p. 45-46) acrescenta que

Nos espaços abertos pelo processo de transição política e redemocratização, ganha visibilidade, também, o embate entre setores privatizantes e segmentos sociais estatizantes, em torno das políticas públicas e de suas derivações, como a distribuição e o uso dos recursos.

Avritzer (2008, p. 53) acrescenta que

...do ponto de vista da participação, o elemento que sobressai naVIII Conferência Nacional de Saúde é a combinação entre a reivindicação de um Estado mais ativista 
por parte do movimento sanitarista e de uma forma popular de controle público por parte dos movimentos populares. (...) A proposta de um sistema unificado de saúde, descentralizado e com participação popular foi apresentada sob a forma de uma emenda popular durante a Assembléia Nacional Constituinte e aprovada com algumas modificações propostas pelos setores conservadores.

Independente dos desdobramentos políticos que sucederam a CNS 8, importa para a análise aqui proposta a maneira pela qual o tema foi encarado nesse fórum que evidenciou distintas visões da sociedade acerca da política de saúde e do papel do Estado nesse campo. Com vistas a demonstrar como algumas características básicas da cultura política brasileira guiam as orientações políticas relativas ao papel do Estado, nos ocuparemos de um breve exame dos anais da CNS 8 (CNS, 1986).

O referido documento possui transcrições das discussões ocorridas dentro dos painéis que foram organizados em três eixos: "Saúde como direito inerente à cidadania e à personalidade", "Reformulação do sistema nacional de saúde" e "Financiamento do setor de saúde". Além disso, o documento também traz resumos e deliberações de todas as pré-conferências estaduais.

A leitura dos relatórios dessas pré-conferências evidencia uma considerável mobilização social com uma participação popular maior se comparada ao encontro nacional. Um assunto recorrente em todos os relatos dessas pré-conferências é a demanda popular por um aumento da participação do Estado como garantidor da saúde. A título de exemplo, destacamos um registro advindo da conferência paraense em que se coloca que "O Estado tem o dever de garantir a saúde da população, não podendo, em hipótese alguma, delegar esse dever a setores privados." (CNS, 1986, p. 349), além de exemplos como o do Espírito Santo em que aprovou-se em plenária a proposta de que

A nova Constituição brasileira deve reconhecer a saúde como um direito fundamental de todos, cabendo ao Estado a responsabilidade de assegurar as condições básicas de vida inerentes ao gozo desse direito e de oferecer assistência de saúde igualitária e isenta de qualquer tipo de discriminação (CNS, 1986, p.356)

No evento final ocorrido de 17 a 21 de março de 1986, em Brasília, adotou-se a dinâmica de apresentações de trabalhos encomendados de especialistas e conseguinte debate sobre o tema abordado com a participação de porta-vozes de diferentes entidades representativas da sociedade civil.

No primeiro debate, as falas dos representantes da Comissão Nacional de Bispos do Brasil (CNBB), da Confederação Nacional das Associações de Moradores (CONAM) e da Central Única dos Trabalhadores
(CUT) reforçaram as mesmas perspectivas trazidas pelas pré-conferências no que tange ao papel do Estado. A única fala parcialmente destoante no debate foi a da representante do Conselho Nacional dos Direitos da Mulher (CNDM) que ao comentar um ponto específico, o dos intentos do governo no controle ou incentivo à natalidade, ressaltou que

A maternidade e a paternidade são direitos individuais, não cabe ao Estado interferir nessas decisões, seja no sentido de restrição, seja no sentido de expansão da prole (CNS, 1986, p.117)

Destaca-se nesse primeiro debate a fala do representante da Federação das Indústrias do Estado de São Paulo (FIESP) que pondera em sua abertura que está ali “...não na qualidade de um dos elementos dos seus quadros, mas sim como um médico..." (CNS, 1986, p. 119). Tal postura pode ser atribuída a uma tentativa de se afastar tanto em discurso quanto em imagem de uma possível oposição a priori de seus ouvintes da visão de um grupo de entidades privadas. Sua intervenção se pauta pela reivindicação de abertura do debate sobre a reforma do sistema de saúde para mais setores da sociedade, como o setor privado:

Nossa mensagem é para que sintamos que teríamos como representantes um grupo de profissionais ligados à atividade das empresas, que poderia bem contribuir para o traçamento dessas políticas nacionais e que, pelos seus conhecimentos e experiência adquirida, trazer a visão do que foi a vida nessas mesmas empresas, no sentido do melhoramento que se espera. (CNS, 1986, p.120)

$\mathrm{Na}$ segunda rodada de debates a mesma tendência de orientações pró-Estado estão presentes. Destaca-se a fala do representante da Federação das Associações de Moradores do Estado do Rio de Janeiro (FAMERJ) que, para além da definição do Estado como principal ator na garantia do direito à saúde, deva assegurar também que os interesses privados não estejam presentes:

Nós imaginamos que é impensável se discutir seriamente como reorganizar o Sistema Nacional de Saúde numa lógica de um dever, o Estado assumindo o provimento como dever, sem se exigir que esse Estado, ao prover a saúde como direito, seja também um Estado que assuma como sua a responsabilidade de prestar os serviços de saúde, assuma como sua a responsabilidade de impedir que se lucre com a saúde, que assuma como sua a responsabilidade de impedir que alguém neste País possa enriquecer às custas da doença da população, pois só assim a saúde será um direito de todos. (CNS, 1986, p. 152)

No debate do terceiro painel, relativo ao financiamento do sistema de saúde, os interlocutores possuíam um perfil mais técnico e se limitaram a realizar consi- 
derações a respeito da fonte ideal dos recursos para o financiamento do novo sistema de saúde. No entanto, em nenhum momento das distintas falas foi questionada a ideia de que o Estado deveria assumir a prevalência na prestação do serviços de saúde.

Independente do encaminhamento dado às propostas emergentes no debate suscitado pela CNS 8, ficou claro no exame das narrativas presentes nesse fórum que há uma atitude generalizada em prol do Estado como o ente garantidor da saúde de todos os indivíduos. Mesmo em posições contrárias ao controle do sistema de saúde pelo Estado, como a de entidades privadas, há um receio quanto a defesa clara desses interesses.

Cabe destacar também que esse espaço da CNS 8 foi apenas um dos fóruns de discussão e formulação das ideias do sistema de saúde criado a partir da nova constituição. Devido a predominância do movimento sanitarista e de outros atores de defesa do sistema de saúde pública na conferência, o setor privado se reorganizou politicamente buscando atuar sobre a assembleia constituinte. Conforme aponta Campos (2007, p. 1869), o SUS acabou por se estabelecer como um sistema híbrido cujas diretrizes seriam "compatíveis tanto com o desenho socializante da tradição européia dos sistemas nacionais, quanto com a tradição norte-americana, liberal-privatista."

\section{Os Estados Unidos e o plano Clinton de Reforma da Saúde}

Nos Estados Unidos, é possível identificar quatro grandes momentos, desde a segunda metade do Século $\mathrm{XX}$, em que um debate mais generalizado sobre políticas públicas de saúde entrou na agenda nacional. Primeiramente, durante os governos de John F. Kennedy e Lyndon Johnson, na primeira metade da década de 1960, em que foi estabelecido um sistema de seguro-saúde para idosos, denominado Medicare.

Em um segundo momento, no início da década de 1970, Richard Nixon consegue realizar uma modesta expansão do Medicare, que passou a cobrir menores de 65 anos com graves deficiências físicas ou problemas renais, mas não teve êxito em suas propostas de universalização da saúde pública. O terceiro momento compreende a tentativa, sem sucesso, do governo de Bill Clinton de realizar uma reforma do sistema nacional de assistência de saúde.

No quarto momento, durante o primeiro governo de Barack Obama é aprovado a Lei de Cuidado Acessível e Proteção ao Paciente (Patient Protection and Affordable Care Act) que representou a maior reforma no sistema de saúde norte-americano das últimas seis décadas.

Em todos esses momentos, o governo norte-americano enfrentou forte oposição da opinião pública, seja ela insuflada ou não pelos grupos de interesse contrários às reformas. Conforme apontam Steinmo e Watts (1995), a explicação cultural é uma das mais recorrentes explicações para a dificuldade de implantação de um sistema nacional público de saúde nos Estados Unidos.

No início dos debates em torno de uma reforma do sistema de saúde no início dos anos 1990, Jacobs (1993, p. 635, tradução nossa) argumenta que as pesquisas de opinião pública evidenciaram a alta ambivalência na cultura política dos Estados Unidos em torno do tema. Enquanto grande parte da população norte-americana declara-se favorável a uma reforma do sistema de saúde e crítica em relação a alguns aspectos da administração dos planos privados, ao mesmo tempo "os norte-americanos abrigam temores bem específicos sobre um envolvimento maior do governo".

Dessa forma, Jacobs (1993) acredita que essa é a situação em que a opinião pública tem menor probabilidade de influenciar políticas públicas, quando é ambígua e fraca em torno de uma proposta. Jacobs e Shapiro (1994, p. 212, tradução nossa) acreditam que realmente existe uma predisposição da sociedade norte-americana a ser resistente quanto à participação do Estado na gestão do sistema de saúde, no entanto, os autores acreditam que nos últimos anos tem havido uma mudança nesse aspecto:

...as atitudes dos norte-americanos em relação ao ati-
vismo governamental tem mudado de um forte anti-es-
tatismo laissez-faire para uma posição mais ambivalente
baseada no pragmatismo...

Ao discutir as razões da inexistência de um sistema nacional público de saúde nos Estados Unidos, Steinmo e Watts (1995, p. 365, tradução nossa) afirmam concordar em parte com os argumentos de que aspectos culturais estariam relacionados a essa questão, no entanto, atentam para a preponderância do papel das instituições nessa relação.

Nós acreditamos que existe uma relação clara entre a desconfiança dos norte-americanos em relação ao governo e a incapacidade governamental de implementar reformas amplas e bem sucedidas de políticas sociais. No entanto, em oposição àqueles culturalistas que aparentemente vêem a relação entre cultura e política pública como uma via de mão única, nós acreditamos que repetidos fracassos das instituições políticas nacionais em lidar adequadamente com os problemas enfrentados pelos norte-americanos inflamaram a desconfiança dentro da política norte-americana.

Ao contrário do caso brasileiro em que foi possível observar, ainda que de maneira não generalizada, o estabelecimento de espaços amplos de discussão que buscaram a participação social, no caso norte-americano não houve a instauração de fóruns sistemáticos que 
procurassem viabilizar o debate com o envolvimento de amplos setores da sociedade.

Especialmente no caso do plano Clinton de 1993, conforme aponta Yankelovich (1995), não houve de fato um envolvimento social nas discussões em torno das propostas do plano, em vez disso, sucedeu-se um conflito contínuo entre elites defensoras ou opositoras ao plano para fazer valer sua vontade e, em um segundo plano, visando também persuadir a opinião pública.

No entanto, duas iniciativas do governo norte-americano à época do plano Clinton buscaram ampliar a participação na elaboração do plano para além da Casa Branca. Uma primeira iniciativa, de cunho simbólico, foram as caravanas de ônibus que partiam de quatro cidades dos EUA em direção à capital, Washington D.C.

Inspirado no movimento dos Freedom Riders, da década de 1960, e copiando uma campanha semelhante que ajudou na eleição do presidente Bill Clinton, essa iniciativa, que ficou conhecida como "Health Security Express", buscava conscientizar a população sobre a necessidade de uma reforma no sistema de saúde divulgando as historias de seus passageiros que contavam experiências pessoais e profissionais de dificuldades em obter assistência de saúde no sistema vigente. Grupos de quatro ônibus seguiam em comboio em cada uma das quatro rotas em direção a cidade de Washington D.C., transportando médicos, enfermeiros, aposentados e ativistas simpáticos à causa de Clinton.

Embora no princípio tenha recebido apoio popular, essa iniciativa experimentou uma crescente oposição durante seu roteiro na medida em que a desaprovação popular ao plano aumentava. Notícias de jornais davam conta de que, a cada parada, protestos eram organizados por opositores do plano. Em uma dessas notícias, um dos integrantes da caravana depõe que "Vários manifestantes nos cercaram. Alguns de nós estávamos em cadeiras de rodas e tivemos dificuldade para nos deslocar. Os manifestantes disseram, 'Nós não deveríamos ter que pagar por sua cadeira de rodas'., - Outra reportagem cobriu a passagem da caravana em Kansas City, marcado por um comício da então primeira-dama Hillary Clinton que, ao ser interpelada por protestos generalizados com gritos de "No big government" e "No socialized medicine", comentou que "Todo esse berreiro e gritaria é o que está realmente ferindo a América hoje [...] Nós estamos gritando muito e ouvindo pouco."7
Outra inciativa, de cunho mais político, foi a criação do "Task Force on National Health Care Reform" que tinha por objetivo preparar a legislação da reforma a ser proposta pelo governo ouvindo todas as partes envolvidas. A única audiência pública ocorrida durante a preparação da reforma deu-se no dia 29 de março de 1993, na Universidade George Washington. Esse evento contou com a realização de 12 painéis de debate conduzidos durante 13 horas pelo Vice-Presidente Al Gore, cada painel contou com cinco ou seis participantes que representavam diversas entidades relacionadas a saúde, desde a Associação Nacional de Aposentados (American Association of Retired Persons) até Associação Nacional de Empresas Privadas (National Association of Private Enteprise). Os debates foram transmitidos e gravados pela rede a cabo de televisão C-SPAN e cujos arquivos de vídeo estão disponíveis em seu website (CSPAN, 1993).

De modo geral, as diversas falas presentes se afastavam de uma discussão mais abstrata de reforma do sistema de saúde, se comparadas as discussões da CNAS 8 , evitando tratar diretamente sobre questões como o papel do Estado ao tempo em que defendiam questões concretas relacionadas aos seus respectivos interesses. A Associação Americana de Enfermeiros (American Nurses Association) defendia uma valorização maior desses profissionais com vistas a redução de custos, o Congresso Nacional de Indígenas Americanos ponderava a necessidade de expandir e melhorar os serviços de saúde específicos a esses povos nos Estados Unidos e, dessa forma, os debates se formaram em torno de uma defesa de interesses específicos de cada segmento ali representado.

Contudo, foi possível observar um elemento latente em diversas narrativas que se contrapunha a uma participação mais incisiva do Estado sobre os serviços de saúde. No segundo painel, com representantes de associações de pequenas empresas, o tópico mais presente foi a oposição a possibilidade de que as empresas arcassem com parte do financiamento da saúde como uma imposição do governo, o que foi caracterizado como "Un-American" pelo representante da Associação Nacional de Restaurantes. Ao ressaltar sua oposição à ideia de obrigação por financiar planos de saúde, esse representante afirma que há inclusive uma parcela da população que não deseja ter planos de saúde: "...a marioria da população jovem da América pensa que não é vulnerável a doenças ou enfermidades, se você perguntar a pessoas com idades de 20 ou $25 \ldots$ em seus 20

6 Davidson, Lee (3 de agosto de 1994). Doctor Decries 'Propaganda' by Opponents of Clinton Plan. Deseret News. Disponível em http://www. deseretnews.com/article/367837/DOCTOR-DECRIES-PROPAGANDA-BY-OPPONENTS-OF-CLINTON-PLAN.html Acesso em 10 de junho de 2013. Tradução nossa.

7 Worthington, Rogers (31 de julho de 1994). Cheers, Hoots Greet Clinton, Reform Bus. Chicago Tribune. Disponível em http://articles.chicagotribune.com/1994-07-31/news/9407310354_1_universal-health-care-legislation-health-security-express-health-care-coverage Acesso em 10 de junho de 2013. Tradução nossa. 
ou 30 anos, eles pensam que são feitos de aço e que eles nunca irão precisar disso." (CSPAN, 1993, Panel 2, $30 \mathrm{~min}$, tradução nossa).

Os painéis contaram com a participação de representantes da indústria farmacêutica, dos provedores privados de plano de saúde e gestores de hospitais privados. Uma questão recorrente nos discursos apresentados foi a necessidade do governo regular a concorrência e não de criar impedimentos burocráticos de competição entre os agentes desse setor o que, nessa visão, traria prejuízos aos cidadãos. Uma fala do representante da Federação Sistemas de Saúde Americanos (Federation of American Health Care Systems) expressa de forma direta uma posição nesse debate:

Existem várias questões complexas nesse debate, mas a questão última, eu acredito, é quem irá controlar um sétimo da economia: o governo ou o povo. [....] O que nós realmente precisamos fazer é, se nós vamos reestruturar um sétimo da economia, o que é uma tarefa enorme, nós iremos colocar o poder nas mãos do povo, o que significa dar a ele escolhas, não significa o governo sentado em Washington ou mesmo em uma capital de estado dizendo ao povo quais hospitais são bons, quais são ruins, quais devem permanecer, quais não devem. [...] o mais importante é que o governo garanta que existam escolhas. A pior coisa que pode acontecer ao nosso sistema de saúde é a existência de somente uma ou duas dessas redes devido as regras governamentais serem tão restritivas que os consumidores não puderam ter escolha. [...] A pior coisa que poderia acontecer seria nós termos que confiar tudo isso ao governo... (CSPAN, 1993, panel 8,27min, tradução nossa)

Essa posição, mesmo em narrativas menos explícitas como as dos representantes de movimentos sociais, entidades religiosas e comunitárias, pondera essa questão do protagonismo da liberdade individual e das decisões tomadas localmente em cada comunidade em contraste com decisões centralizadas tomadas pelo governo estadual ou federal.

Essas narrativas vão ao encontro das conclusões de Quadagno (2005) a respeito das razões dos Estados Unidos não possuírem uma política de saúde universal. Embora a autora enfatize a força dos grupos de interesse do setor privado da área de saúde, ela também reconhece a validade do argumento de que existe uma abertura dentro da cultura política norte-americana para a propagação desses interesses. A seguinte passagem de Quadagno (2005, p. 15, tradução nossa) resume essa ideia:

De acordo um argumento comum, o principal impedimento para um sistema de proteção de saúde nacional tem sido uma cultura política anti-estatista. Porque os norte-americanos dão honras à propriedade privada, tem como sagrado os direitos individuais, e desconfiam da autoridade do Estado, os reformadores encontram dificuldades de tornar convincente o financiamento governamental da saúde. A ambivalência dos norte-americanos em relação ao governo e seu viés de soluções privadas para problemas públicos se colocam no meio do caminho. [...] A desconfiança em relação ao governo abalou a confiança pública no plano de saúde de Clinton, permitindo seus oponentes afirmar que os burocratas federais iriam destruir as relações médicopaciente e retirar o direito do povo de escolher seus próprios médicos.

$\mathrm{Ou}$ seja, não se atribui exclusivamente às características da cultura política dos norte-americanos a dificuldade de implementação de um sistema público universal de saúde nos Estados Unidos. No entanto, essa dimensão cultural ajuda a compreender o clima de reprovação da opinião pública a determinadas iniciativas do governo nesse setor, bem como o jogo de interesses políticos que ambientam essa discussão.

\section{Cultura política e políticas de saúde}

Quando provocadas por situações que exigiam a defesa de uma visão acerca do indivíduo, da sociedade e do Estado, as visões e narrativas aqui esmiuçadas se apresentaram como expressões de visões mais profundas acerca do mundo político, em outras palavras, como expressões da cultura política.

Nesse trabalho, foram buscados novos caminhos que pudessem expandir o espectro de visão sobre a cultura política para além das recorrentes análises de pesquisas do tipo survey que se encontram em estudos nessa área. Recorreu-se aqui à apreciação de dois casos que expuseram visões e narrativas portadoras de significados que, por limitações metodológicas, não podem usualmente ser acessada de maneira satisfatória por meio de outras metodologias.

Pode-se, dessa maneira, relacionar essa análise empírica de dois momentos específicos da história política brasileira e norte-americana com a discussão teórica acerca da cultura política desses dois países. Apresenta-se relevante a formulação de Fukuyama (2011, p. 9) que acredita haver nos Estados Unidos uma cultura política que "emphasizes equality of opportunity rather than of outcomes", em contraste a cultura política brasileira, podemos afirmar, enfatiza uma ideia abstrata de igualdade de resultados em detrimento de uma perspectiva mais concreta sobre a igualdade de oportunidades. Essas duas matrizes distintas de cultura política possuem implicações diretas para as orientações individuais relacionadas ao papel do Estado que por um lado pode ser tido como o depositário das esperanças de garantia da justiça social mas por outro é enxergado como um 
entrave ao pleno exercício da liberdade individual e igualdade social.

É importante destacar, também, que a análise aqui engendrada não vai além das perspectivas dos atores envolvidos no processo. Não foi objetivo estudar como acabaram sendo estabelecidos de fato os sistemas de saúde ou o seus desempenhos. Procurou-se investigar aqui as narrativas que embasaram as reformas e formulações dos sistemas de saúde, em que pese sua distância em relação ao que de fato foi implementado, ou seja, as concepções acerca do papel do Estado no sistema de saúde e não o real papel que o Estado desempenha. $\mathrm{O}$ que importa observar é que essas visões acerca do papel do Estado e das políticas públicas estão imbricadas em uma cultura política distinta em cada caso estudado.

Convém apontar também as limitações da análise aqui realizada. Ao selecionar o tema saúde, partiu-se da suposição de que os diferentes aspectos da cultura política expressos no debate em torno do tema saúde são tão internalizados que seriam possíveis de ser transpostos a qualquer outra área relativa a atuação do Estado, enquanto, a bem da verdade, essa é apenas uma suposição teórica sujeita a um teste empírico não realizado aqui.

\section{Considerações finais}

A análise dos discursos inseridos no espaço da VIII Conferência Nacional da Saúde apontou para uma reafirmação da dicotomia entre responsabilidade individual ou privada e responsabilidade do Estado. Nota-se, sobretudo entre as narrativas dos representantes em movimentos de base social, uma posição mais favorável ao papel ativo do Estado no sistema de saúde em contraposição a uma posição sequer mencionada, dando lugar à ênfase na escolha individual, que se vê presente nas narrativas selecionadas nos Estados Unidos.

Cabe destacar, ainda, que todo o processo de preparação da CNS no Brasil e a própria conferência tiveram como pano de fundo o processo de redemocratização brasileiro em que seria razoável se esperar uma posição contrária ao intervencionismo do Estado em virtude dos seguidos anos de autoritarismo e do amplo desejo pela participação social. No entanto, o que se viu foi a expressão de uma cultura que apoia de forma mais aberta a intervenção do Estado ou, de maneira equivalente, desconfia mais dos setores privados do que dos setores públicos em áreas sociais. Como pontuou um representante da CUT na conferência nacional de saúde (CNS, 1986, p. 119): "Sob a égide de que a estatização pode ser autoritária podemos assistir á abertura da porta, escancaradamente, apesar do discurso, á iniciativa privada". Enxergando nessa uma ameaça ainda maior.

Faz-se necessária uma ressalva nessa comparação entre a implementação do SUS e a discussão relativa ao Health Care Reform que é marcada por uma aguda diferença entre as duas sociedades. No Brasil, falamos da implantação de um sistema que buscava levar assistência de saúde à maior parte da população em um momento em que ela era majoritariamente desprovida desse serviço. Claramente, a opinião pública tendia de qualquer forma a ser favorável da transformação do sistema para um mais inclusivo. Nos Estados Unidos, mesmo com grande parte da população não possuindo plano de saúde, a maior parte dos cidadãos possuía, então, recursos financeiros para pagar por uma assistência médica privada, seja de maneira individual ou por meio de convênio de seu empregador.

Ainda assim, mesmo considerando esses aspectos que tornam a comparação complexa, é evidente a existência de um espectro que determina até que ponto é possível considerar a intervenção do Estado sobre a sociedade e até que ponto é possível garantir a liberdade individual. Esse espectro está basicamente constrito por orientações políticas que decorrem da cultura política desses países. Isto é, existem questões relativas ao papel do Estado na provisão de saúde no Brasil que não poderiam sequer ser pensadas, pois não possuiriam significado, em um debate mais amplo na sociedade norte-americana e vice-versa.

\section{Referências}

ALMEIDA, Alberto Carlos. A cabeça do brasileiro. Rio de Janeiro: Record, 2007.

AVRITZER, Leonardo. Instituições participativas e desenho institucional: algumas considerações sobre a variação da participação no Brasil democrático. Opin. Publica, Campinas, v. 14, n. 1, June 2008 .

CAMPOS, Gastão Wagner de Sousa. O SUS entre a tradição dos Sistemas Nacionais e o modo liberal-privado para organizar o cuidado à saúde. Ciênc. saúde coletiva, Rio de Janeiro , v. 12, supl. p. 1865-1874, Nov. 2007.

CARDOSO, Fernando Henrique. Pensadores que inventaram o Brasil. São Paulo : Companhia das Letras, 2013.

CONFERÊNCIA NACIONAL DE SAÚDE (CNS), 8, 1986, Brasília, Anais. Brasília: Centro de Documentação do Ministério da Saúde, 1987.

CSPAN. Health Care Reform Panels. C-SPAN, Washington, D.C. March 29, 1993. Disponível em http://www.c-span. org/video/?39151-1 Acesso em 3 de junho de 2013.

FALEIROS, Vicente de Paula et al. A Construção do SUS. Histórias da Reforma Sanitária e do Processo Participativo. Brasília: Ministério da Saúde, 2006. 297 p

FAORO, Raymundo Faoro. Os donos do poder: formação do patronato político brasileiro. 3. ed. rev. São Paulo: Globo, 2001. FREYRE, Gilberto. Casa-grande \& senzala: formação da família brasileira sob o regime da economia patriarcal. São Paulo: Global, 2003.

FUKUYAMA, Francis. The origins of political order: from prehuman times to the French Revolution. London, Profile books, 2011. 
HOLANDA, Sérgio Buarque de. Raízes do Brasil (26a ed.). São Paulo: Companhia das Letras, 1995.

JACOBS, Lawrence. Health Reform Impasse: The Politics of American Ambivalence toward Government. Journal of Health Politics, Policy and Law 18:629-55. 1993.

JACOBS, Lawrence R.; SHAPIRO, Robert Y. Public opinion's tilt against private enterprise. Health Affairs, v. 13, n. 1, p. 285-298, 1994.

KING, Anthony. "Ideas, Institutions and the Policies of Governments: A Comparative Analysis - Part III”, British Journal of Political Science 3 (1973) 409-23.

QUADAGNO, Jill. One Nation Uninsured: Why the U.S. Has no National Health Insurance. New York: Oxford University Press, 2005.
LIPSET, Seymour Martin. American exceptionalism. New York: WW Norton. 1996.

STEINMO, Sven; WATTS, Jon. "It's the Institutions, Stupid! Why Comprehensive National Health Insurance Always Fails in America". Journal of Health Politics, Policy and Law. 20 (2): 329.1995

TOQUEVILLE, Alexis de. A democracia na América: leis e costumes - de certas leis e certos costumes políticos que foram naturalmente sugeridos aos americanos por seu estado social democrático. São Paulo: Martins Fontes, 2005.

YANKELOVICH, Daniel. "The Debate That Wasn't: The Public and the Clinton Plan." Health Affairs 14 (Spring): 8-23. 1995.

\title{
Political values and the building of public health care systems in Brazil and in the United States
}

\begin{abstract}
The article explores the relationship between the prevailing political views in society and the debate regarding the construction of national health care systems in Brazil and the United States. According to recent surveys, the opinions about the government's role in health care differ significantly between the U.S. and Brazilian societies. These opinions are linked to more profound characteristics of political culture in these two countries. The analysis of discourses and narratives that were present in debates about the construction of the Sistema Único de Saúde in Brazil and the U.S. plan for health care reform, in the 1990s, show how political values and attitudes linked to these political culture characteristics permeate the policy debate and are valuable to comprehend policy decisions.
\end{abstract}

Keywords: political culture; health policy; Brazil; United States

\section{Valores políticos y construcción de sistemas públicos de salud en Brasil y Estados Unidos}

\section{Resumen}

El artículo investiga la relación entre las opiniones políticas que prevalecen en la sociedad y el debate en torno a la construcción de los sistemas de salud nacionales en Brasil y Estados Unidos. Según encuestas recientes, las opiniones sobre el papel del gobierno en la atención sanitaria difieren significativamente entre los EE.UU. y sociedades brasileñas. Estas opiniones están vinculadas a las características más profundas de la cultura política en estos dos países. El análisis de los discursos y narrativas que estaban presentes en los debates sobre la construcción del Sistema Único de Salud en Brasil y en el plan de Estados Unidos para la reforma de salud, en la década de 1990, muestra cómo los valores y las actitudes políticas vinculadas a estas características de cultura política están impregnados en el debate político y son valiosos para comprender las decisiones políticas.

Palabras clave: cultura política; políticas de salud; Brasil; Estados Unidos 